\title{
Interval Cancers after a Negative Colonoscopy Finding in a Korean Population: A Small Step for Gastroenterologists but One Giant Leap for Koreans
}

\author{
Jae Myung Cha \\ Department of Internal Medicine, Kyung Hee University Hospital at Gang Dong, Kyung Hee University College of Medicine, Seoul, Korea
}

The incidence of colorectal cancer (CRC) in Korea has increased markedly in recent years. This epidemiological change requires CRC screening to reduce the CRC incidence and CRC-related mortality in Korea. A number of observational studies have shown the risk for CRC to be low within the 10-year screening interval after a negative colonoscopy. ${ }^{1}$ Nevertheless, interval cancers occur, especially in the right colon. ${ }^{2}$ Most previous studies on interval cancers after colonoscopy relied on registry or administrative data from Canada or the United States, ${ }^{3-7}$ and the quality of colonoscopic data might differ between countries. Therefore, the prevalence and predictors of interval cancer in the Korean population have been undisclosed. In this regard, I read with great interest the study by Kim et al., ${ }^{8}$ who are to be congratulated for their clinical study showing the prevalence, clinicopathological characteristics, and predictors of interval cancers in the Korean population. However, I have concerns about the study methodology and therefore the conclusions drawn.

In the study by Kim et al., ${ }^{8}$ the prevalence of interval cancer was $6.2 \%$ (30 cases among 482 patients). However, this result may be limited by referral, selection, and recall biases, as it was based on data obtained via telephone calls from a single tertiary referral center. In general, the prevalence of interval

Received January 2, 2014. Revised January 5, 2014.

Accepted January 5, 2014.

Correspondence to Jae Myung Cha, Department of Internal Medicine,

Kyung Hee University Hospital at Gang Dong, Kyung Hee University College

of Medicine, 892 Dongnam-ro, Gangdong-gu, Seoul 134-727, Korea. Tel:

+82-2-440-6113, Fax: +82-2-440-6295, E-mail: drcha@khu.ac.kr

Financial support: None. Conflict of interest: None. cancer may correctly be assessed by conducting a populationbased study, and the prevalence of interval cancer based on a population study in the West was $4.0 \%-7.9 \%$. ${ }^{4-7,9,10}$

Kim et al. ${ }^{8}$ also suggested that young age and right-side location were independent factors associated with interval cancer in a multivariate analysis. In a recent study from Canada, however, female sex, older age, and performance of the colonoscopy by a non-gastroenterologist were identified as predictors of interval cancers after a negative colonoscopy. ${ }^{3,4}$ Although other authors suggested the accelerated tumor biology in young patients as a cause of interval cancer, the authors of the Canadian studies ${ }^{3,4}$ suggested that a deficiency in the quality of colonoscopic data rather than accelerated tumor biology was the cause of most of the interval cancers occurring after a negative colonoscopy. Furthermore, information on family CRC history or hereditary syndromes was not described by Kim et al.; therefore, their study might have been unable to evaluate the age impact on interval cancers, as young age in familial CRC may have a confounding effect on the interval cancer.

As pointed out by the authors, it would be better if quality colonoscopic data such as bowel preparation, completeness, and adenoma detection rate, as well as qualifications of endoscopists, were assessed as predictors of the occurrence of interval cancers. Considering the wide variation in the detection rates of adenomas and serrated polyps between endoscopists, the quality of colonoscopic data should be stressed and assessed as a predictor of interval cancers. However, to answer these questions, a population-based cohort design with complete follow-up might be warranted.

While we applaud the investigators for obtaining Korean

๑ Copyright 2014. Korean Association for the Study of Intestinal Diseases. All rights reserved.

This is an Open Access article distributed under the terms of the Creative Commons Attribution Non-Commercial License (http://creativecommons.org/licenses/by-nc/3.0)

which permits unrestricted non-commercial use, distribution, and reproduction in any medium, provided the original work is properly cited. 
data about interval cancer for the first time, which might be a small step for gastroenterologists but a giant leap for Koreans, methodological issues need to be addressed before conclusive results can be drawn from their study about the prevalence and predictors of interval cancers in the Korean population.

\section{REFERENCES}

1. Singh H, Turner D, Xue L, Targownik LE, Bernstein CN. Risk of developing colorectal cancer following a negative colonoscopy examination: evidence for a 10-year interval between colonoscopies. JAMA 2006;295:2366-2373.

2. Brenner H, Chang-Claude J, Seiler CM, Sturmer T, Hoffmeister $\mathrm{M}$. Does a negative screening colonoscopy ever need to be repeated? Gut 2006;55:1145-1150.

3. Singh H, Nugent Z, Mahmud SM, Demers AA, Bernstein CN. Predictors of colorectal cancer after negative colonoscopy: a population-based study. Am J Gastroenterol 2010;105:663-673.

4. Singh H, Nugent Z, Demers AA, Bernstein CN. Rate and predictors of early/missed colorectal cancers after colonoscopy in Manitoba: a population-based study. Am J Gastroenterol 2010;105:2588-2596.

5. Farrar WD, Sawhney MS, Nelson DB, Lederle FA, Bond JH. Colorectal cancers found after a complete colonoscopy. Clin Gastroenterol Hepatol 2006;4:1259-1264.

6. Bressler B, Paszat LF, Vinden C, Li C, He J, Rabeneck L. Colonoscopic miss rates for right-sided colon cancer: a populationbased analysis. Gastroenterology 2004;127:452-456.

7. Bressler B, Paszat LF, Chen Z, Rothwell DM, Vinden C, Rabeneck L. Rates of new or missed colorectal cancers after colonoscopy and their risk factors: a population-based analysis. Gastroenterology 2007;132:96-102.

8. Kim CJ, Jung YS, Park JH, et al. Prevalence, clinicopathologic characteristics, and predictors of interval colorectal cancers in Korean population. Intest Res 2013;11:178-183

9. Cooper GS, Xu F, Barnholtz Sloan JS, Schluchter MD, Koroukian SM. Prevalence and predictors of interval colorectal cancers in medicare beneficiaries. Cancer 2012;118:3044-3052.

10. Brenner H, Chang-Claude J, Seiler CM, Hoffmeister M. Interval cancers after negative colonoscopy: population-based casecontrol study. Gut 2012;61:1576-1582. 